\title{
A gestão pedagógica no contexto das avaliações externas e em larga escala
}

\author{
Pedagogical management in the context of external and large scale assessments
}

\begin{abstract}
Luziane Said Cometti Lélis
Mestre em Educação pela Universidade Federal do Pará, Coordenadora Pedagógica da Secretaria Municipal de Educação do Município de Belém (PA) e Docente da Secretaria de Estado de Educação do Pará. Membro do Grupo de Estudos e Pesquisas em Estado, Política e Gestão de Sistemas e Organizações Educacionais.
\end{abstract} luziane.bim@gmail.com

\begin{abstract}
Dinair Leal da Hora Doutora em Educação pela Universidade Estadual de Campinas, Docente Permanente da universidade Federal do Pará nos Programas de Pós-Graduação em Currículo e Gestão da Escola Básica e Educação na Amazônia. Coordenadora do Curso de Doutorado em Educação na Amazônia - EDUCANORTE - Associação em Rede. Líder do Grupo de Estudos e Pesquisas em Estado, Política e Gestão de Sistemas e Organizações Educacionais. tucupi@uol.com.bredinairleal@ufpa.br
\end{abstract}

Resumo: $\mathrm{O}$ estudo apresenta reflexões sobre o papel da gestão pedagógica, as definições, atribuições e desafios no contexto de uma nova lógica de organização educacional pautada na cultura de resultados. $\mathrm{O}$ objetivo é discutir as concepções e práticas da gestão pedagógica da escola básica e sua relação com a apropriação dos resultados das avaliações externas. Fundamentada numa abordagem qualitativa, a pesquisa de campo foi realizada em uma escola pública municipal em Belém/PA, por meio de entrevista semiestruturada com gestores pedagógicos e professores. A investigação indica a necessidade de discussão coletiva sobre o uso pedagógico dos resultados das avaliações externas no ambiente escolar, pois estão modificando os fazeres pedagógicos (mais dos professores) na busca de resultados mensuráveis, sem a construção de novos saberes na realização da melhoria de ensino; e que compete aos gestores pedagógicos a condução do processo de divulgação, estudo e reflexão dos dados advindos dessas avaliações, numa perspectiva emancipatória.

Palavras-chave: Gestão Pedagógica. Avaliação Externa. Cultura de resultados. Apropriação de resultados.

\begin{abstract}
The study presents reflections on the role of pedagogical management, the definitions, attributions and challenges in the context of a new logic of educational organization based on the culture of results. The objective is to discuss the conceptions and practices of the pedagogical management of the elementary school and its relation with the appropriation of the results of the external assessments. Based on a qualitative approach, the field research was conducted at a municipal public school in Belém / PA, through semi-structured interviews with pedagogical managers and teachers. The research indicates the need for collective discussion about the pedagogical use of the results of external assessments in the school environment, as they are changing the pedagogical practices (more of teachers) in search of measurable results, without the construction of new knowledge in the realization of teaching improvement. ; and that it is up to the pedagogical managers to conduct the process of dissemination, study and reflection of the data from these assessments, in an emancipatory perspective.
\end{abstract}

Keywords: Pedagogical Management. External Assessment. Results culture. Appropriation of results. 


\section{Introdução}

A gestão pedagógica representa o conjunto de ações educativas - mediação, articulação e formação - desenvolvidas no ambiente escolar, com vistas à melhoria dos processos de ensinoaprendizagem e ao desenvolvimento humano. Muito embora, essas três principais dimensões das ações educativas simbolizem a essência do trabalho pedagógico, não são exclusivas dos coordenadores pedagógicos, mas também dos diretores escolares.

É fundamental que os gestores pedagógicos (coordenadores e diretores), principalmente os que atuam na educação básica, desempenhem as funções administrativas e pedagógicas de forma coletiva, visando o sucesso escolar. Para tanto, autores entre os quais Paro, (2011) e Pinto (2011) defendem a articulação entre os aspectos administrativos e pedagógicos.

A gestão na organização do trabalho pedagógico realiza suas ações por meio de uma atividade intencional, estruturada e coordenada, realizada com todos os sujeitos que compõem o espaço educativo nas atividades de planejamento, discussão do projeto pedagógico, currículo, planos de ensino e avaliação.

Não obstante, em face à multiplicidade de tarefas presentes no enfrentamento do cotidiano escolar, o coordenador pedagógico acaba assumindo atribuições que não são próprias da profissão e vai constituindo-se na sua identidade profissional e desviando o foco do seu trabalho, principalmente num contexto marcado pela implementação das políticas neoliberais no campo da educação.

As atuais políticas educativas baseiam-se em modelos gerenciais, geralmente constituídas de bonificações para o alcance de metas, que simplificam e reduzem os problemas educacionais à problemas técnicos de gestão e gerenciamento escolar, levando a transferência de obrigação e responsabilidades à escola (HYPÓLITO, 2008).

A introdução desses novos valores na gestão vai alterando o trabalho dos gestores pedagógicos nas escolas e, no seu limite, comprometendo o processo de democratização dos sistemas escolares. O novo gerencialismo adotado na educação vai de encontro às perspectivas democráticas que sustentamos ser imprescindível para orientar as práticas pedagógicas, ainda em processo de construção no ambiente escolar, porque omite a especificação do trabalho pedagógico.

O estudo traz uma reflexão a respeito do papel da gestão pedagógica, as definições, as atribuições e os desafios no contexto de uma nova lógica de organização educacional pautada na cultura de resultados. O objetivo é discutir as concepções e práticas da gestão pedagógica da escola básica e sua relação com a apropriação dos resultados das avaliações externas. 
A pesquisa fundamenta-se numa abordagem qualitativa pela necessidade de se obter em campo as percepções e representações a respeito da avaliação externa e do seu processo de apropriação dos resultados, em uma escola pública municipal de Belém/PA. Para tanto, a entrevista semiestruturada foi utilizada como técnica de coleta de dados, com 02 gestores, 02 coordenadores pedagógicos e 04 professores.

Os dados coletados nos depoimentos dos profissionais entrevistados foram interpretados por meio da análise de conteúdo, enredado pelo referencial teórico utilizado para a compreensão do objeto de estudo. Assim, o artigo apresenta-se estruturado em duas seções que se complementam: gestão pedagógica: definições e atribuições; gestão pedagógica e avaliação externa; e as considerações finais.

\section{Gestão pedagógica: definições e atribuições}

Para iniciar a discussão direcionada ao trabalho da gestão pedagógica no contexto escolar, faz-se necessário compreender o significado de "gestão pedagógica", a partir das contribuições de Libâneo, Oliveira e Toshi (2012), Ferreira (2008) e Koetz (2010).

Libâneo, Oliveira e Toshi (2012) reconhecem a necessária participação de todos os membros da escola em função da aprendizagem, contudo, não perdem de vista o caráter hierárquico da função e da especificidade técnica de cada trabalho pedagógico. Desta forma,

\footnotetext{
embora a integração e a articulação entre meios e objetivos sejam da responsabilidade de todos os membros da equipe escolar, cabe maior responsabilidade, especificamente, à direção e à coordenação pedagógica, as quais, no âmbito da escola, respondem de forma mais direta pelas condições e meios de realização do trabalho dos professores na sala de aula (p. 426-427).
}

Libâneo, Oliveira e Toshi (2012) enfatizam, também, a especificidade técnica relativa à função de dirigentes escolares (direção e coordenação) definindo-os como gestores, e afirmam que essa mesma definição (gestores), “[...] é igualmente aplicável aos professores, seja em seu trabalho na sala de aula, seja quando são investidos de responsabilidades no âmbito da organização escolar” (p. 474).

Ferreira (2008), diante de tantos e imprecisos usos do termo pedagógico presentes no cotidiano, salienta uma distinção entre gestão pedagógica (ação de gestores em atividades pedagógicas) e gestão do pedagógico (trabalho dos professores que acontece na aula). Para a autora, pensar a gestão do pedagógico significa mudar a compreensão da organização escolar, 
"eliminando centralidades hierárquicas, concentração de decisões e fazendo a linguagem circular" (Idem, 2008, p. 187).

Koetz (2010) utiliza o termo equipe diretiva, formada geralmente pelo diretor, vice (s)diretor (res), coordenador (es) pedagógico (s) e orientador (es) educacional (ais), como responsável (veis) pela organização e coordenação do trabalho pedagógico, sem desconsiderar a prática de agir de forma reflexiva na gestão. Desta forma, defende uma perspectiva de gestão democrática, em que toma o diálogo como estratégia para buscar soluções do cotidiano com a comunidade escolar, inclusive a respeito das avaliações em larga escala.

A definição de gestão pedagógica utilizada neste estudo refere-se à ação de gestores (diretor e coordenador) na organização do trabalho escolar, articulada com a atividade do professor que acontece dentro e fora da sala de aula, ambas objetivando a produção do conhecimento, considerando também, que a ação do diretor e do coordenador só se realiza em função da aprendizagem, desenvolvida diretamente pelo trabalho docente e que, somados, integram a gestão pedagógica da escola.

A gestão pedagógica representa um conjunto de todas as práticas educativas desenvolvidas na escola, que toma como referência os processos de ensino e aprendizagem que acontecem entre professores e alunos, indo além dos limites da sala de aula (PINTO, 2011). Trata-se de uma compreensão do caráter pedagógico associado ao caráter administrativo em função da aprendizagem dos alunos e consequentemente, do sucesso escolar.

Essa visão encontra respaldo no entendimento de Paro (2011, p.39) sobre as ações da escola com vistas à realização de seus fins, pois “se administração é utilização racional de recursos para a realização de fins, atividade portanto mediadora entre meios e objetivos, o processo pedagógico necessariamente adquire uma conotação administrativa".

As tarefas administrativas e pedagógicas complementam-se no contexto escolar e, dependendo da concepção de gestão assumida pelos atores da escola, poderá realizar uma maior aproximação entre as funções administrativas e pedagógicas, entre diretor, coordenadores e professores, o que irá contribuir para a melhor organização do trabalho pedagógico. Afinal, vale destacar que as políticas de avaliação nacional emergem de uma concepção de gestão gerencial no ambiente escolar, o que não propicia a integração dessas funções.

A esse respeito, Domingues (2014) ressalta que o diretor de escola, mesmo se ocupando de tarefas mais administrativas e burocráticas, 
tem sua função diretamente ligada ao pedagógico, e seu distanciamento ou aproximação está associado às diferentes concepções de gestão de escola, às demandas estabelecidas com o coordenador pedagógico e ao projeto desenvolvido na unidade educativa ( $\mathrm{p}$. 103).

A compreensão de uma gestão que busca a articulação entre os aspectos administrativos e pedagógicos do processo educacional está relacionada com a postura e o compromisso político dos gestores e, principalmente do diretor, portanto, "essas atribuições administrativas devem ser sempre assumidas com clareza do vínculo que estabelecem com o serviço pedagógico e de sua submissão a ele" (PINTO, 2011, p. 176). Essa percepção está presente no discurso da diretora entrevistada nesta pesquisa, ao dizer que:

"[...] administrar falta, frequência é necessário e faz parte do processo de gestão, mas tem que olhar o pedagógico, como está o desenvolvimento dos trabalhos, acompanhar junto com a coordenação pedagógica” (D.1)

Desse modo, diretor e coordenador pedagógico assumem a responsabilidade de coordenar e acompanhar o trabalho do grupo, para assegurar:

a) a execução coordenada e integral de atividades dos setores e indivíduos da escola, conforme decisões coletivas anteriormente tomadas; b) o processo participativo de tomada de decisões, atentando, ao mesmo tempo, para que estas se convertam em medidas concretas efetivamente cumpridas pelo setor ou pelas pessoas em cujo trabalho são aplicadas; c) articulação das relações interpessoais na escola e no âmbito em que o dirigente desempenha suas funções (LIBÂNEO; OLIVEIRA; TOSHI, 2012, p. 475)

Os gestores pedagógicos têm atribuições próprias inerentes a sua função de diretor ou coordenador. O trabalho do diretor é composto de funções pedagógicas e administrativas mas, em geral, sua atuação está mais diretamente ligada aos aspectos administrativos, e os aspectos pedagógico curriculares ficam a cargo da coordenação pedagógica. A escola pesquisada, não foge à essa realidade.

Para viabilizar o trabalho pedagógico em função da qualidade do ensino, a coordenação pedagógica desenvolve uma série de atribuições destacadas, como:

o acompanhamento das atividades de sala de aula, em atitude de colaboração com o professor da classe; a supervisão da elaboração de diagnósticos, para o projeto pedagógico-curricular da escola e para outros planos e projetos; a orientação da organização curricular e o desenvolvimento do currículo, incluindo a assistência direta aos professores na elaboração dos planos de ensino, na escolha dos livros didáticos, nas práticas de avaliação da aprendizagem; a coordenação de reuniões pedagógicas e entrevistas com professores, para promover relação horizontal e vertical entre disciplinas, estimular a realização de projetos conjuntos entre os professores, diagnosticar problemas de ensino-aprendizagem, adotando medidas pedagógicas preventivas, e adequar conteúdos, metodologias e práticas avaliatórias; a proposição e a coordenação de atividades de formação continuada e de desenvolvimento profissional dos professores (LIBÂNEO; OLIVEIRA; TOSHI, 2012, p. 501-502). 
Assim, fica destacada a importância do trabalho coletivo dos gestores na coordenação, o que requer uma formação específica (ocupada por pedagogos), com vistas à busca de soluções para encaminhar situações inerentes ao processo educativo.

As incertezas sobre o propósito e a função do pedagogo, marcadas historicamente (ARANTES; GEBRAN, 2014), refletidas pela ausência de uma formação inicial de base sólida de conhecimentos para o enfrentamento dos desafios vividos no cotidiano escolar, contribuiu entre outros fatores, para a falta de identidade deste profissional.

"Ainda hoje, muitos profissionais não têm total clareza da identidade e delimitação de sua competência na vida escolar. A não definição acaba por favorecer situações de desvios no desenvolvimento do seu trabalho" (LIMA; SANTOS; SILVA, 2012, p.2), fazendo-o a assumir tarefas que não são de sua competência.

Segundo as autoras, é necessário que o sujeito compreenda e entenda suas atribuições na profissão que atua, para que

[...] possa utilizar todo o seu potencial. No caso do coordenador pedagógico no Brasil, a falta de uma identidade profissional definida tanto por aquele que exercer a profissão quanto à legislação que a legitima é um dos grandes problemas que vem se configurando nas escolas particulares e nas de rede pública de ensino por quase todo país (Idem, p. 3).

Entretanto, ser um diretor ou um coordenador pedagógico que não tenha uma formação docente, pode provocar processos mais fragmentados na organização do trabalho pedagógico.

As identificações e não identificações que o coordenador assume em relação às atribuições que aparecem no enfrentamento do cotidiano escolar acabam gerando uma tensão entre o seu desejo de ser e assumir determinadas formas identitárias e o que os outros esperam que este seja ou assuma (PLACCO; ALMEIDA; SOUZA, 2015). Segundo Placco e Sousa (2012, p.17), os coordenadores pedagógicos

ao assumir atribuições diversas e por vezes contraditórias, revela uma identidade de solucionador de problemas, 'apagador de incêndios', recebendo, em contrapartida, demandas a ela relacionadas, num movimento dialético de atribuição e pertença.

$\mathrm{Na}$ proporção em que este profissional vai assumindo tarefas que não são originariamente suas como se fossem uma missão que não oferecessem opção de escolha, essas tarefas vão constituindo-se, continuamente, na sua identidade profissional.

Embora haja, diariamente, alta demanda de trabalho na escola, em função de emergências e situações imprevistas, não menos importante que as atribuições próprias, os coordenadores 
pedagógicos, acabam desempenhando um acúmulo de tarefas, não estabelecendo limites para o desenvolvimento sistemático de sua prática, como evidencia uma coordenadora entrevistada:

[...] são tantas atribuições do coordenador, temos que fazer a entrada do aluno, atender o pai, tapar buraco dos professores que não veem ou chegam atrasados $[\ldots]$ muitas vezes a questão do plano de aula, o plano de curso, a gente não está acompanhando (C.1).

Os coordenadores pedagógicos possuem uma série de atribuições, previstas em lei, relacionadas às atividades de planejamento, organização, coordenação, avaliação, acompanhamento do processo de ensino e aprendizagem, assistência técnica e formativa aos professores, entre outras. Contudo, esses profissionais são absorvidos pela dinâmica escolar, especialmente, na escola básica pública, substituindo o seu planejamento pelas situações emergenciais e, no limite, deixando escapar algumas de suas funções principais, entre elas o assessoramento ao trabalho docente.

Alguns professores disseram que procuram com frequência os Coordenadores Pedagógicos, porém, muitas vezes, retornam sem o atendimento porque estão com a sala cheia de alunos ou pais. Uma coordenadora pedagógica afirma que:

[...] na própria HP, a coordenação pode estar desenvolvendo o trabalho com o professor, mas muitas das vezes a deixa para resolver situações recorrentes, como: receber material, situações de documentação na secretaria, ocorrência de alunos, atendimento aos pais (C.1).

Outrossim, apesar de demandar grande parte do tempo com questões técnicas, burocráticas e até imprevistas, identificamos na escola em estudo uma gestão pedagógica que estabelece significativa relação de parceria com os professores em reuniões ou nos momentos em que acompanham a Hora Pedagógica (HP), abrindo espaço para discussão e troca de experiências sobre questões de ensino, práticas pedagógicas e acompanhamento discente.

Pinto (2011, p.153) afirma que "o pedagogo, ao prestar assistência pedagógico-didática aos professores, está mediando as práticas docentes em sala de aula". Essa ação do pedagogo ou dos gestores pedagógicos pode contribuir favoravelmente para o "processo de construção do saber fazer docente" (Idem, p.163) e, consequentemente, para a qualidade do ensino.

Para Domingues (2014), ter a formação docente como princípio para propor a melhora da qualidade do ensino, 
significa pensar a complexa tarefa desenvolvida pelo coordenador pedagógico e as condições necessárias para que esse profissional atue de modo a favorecer a articulação do projeto político-pedagógico, dos momentos de reflexão, da troca de experiência e das demandas relacionadas ao acompanhamento da ação pedagógica (p. 16).

Isso colabora, segundo a autora, com uma atuação mais intelectual e não mais meramente técnica e burocrática da coordenação pedagógica, como percebemos no depoimento de alguns professores entrevistados, quando descreviam a gestão pedagógica realizada na escola:

[...] eu percebo que não tem uma preocupação muito grande com relação à atividade do professor em sala de aula, é mais uma atenção voltada por questões muito burocráticas, questões legais que têm que ser seguidas pelo sistema, que solicita. Eu acredito que deva ser bastante cobrada, eu vejo mais uma cobrança dessas questões burocráticas, como diário, coisas deste tipo, e eu acho que poderia estar mais voltada para questões de sala de aula, do trabalho do professor (P.3);

[...] a gestão pedagógica se esforça para fazer o trabalho mais voltado à educação, ao mesmo tempo ela fica fazendo um trabalho paralelo quase de assistência social, de observação das carências dos alunos e da questão da família, que a parte pedagógica fica um pouquinho sacrificada (P.1).

Os professores creditam importância ao papel da coordenação pedagógica no encaminhamento de ações que visem o pleno desenvolvimento das atividades em sala de aula, reconhecendo o esforço empreendido para atender às solicitações, mesmo sendo impossibilitada, às vezes por questões de falta de material e estrutura física do prédio. Nesse rumo, seus depoimentos são reveladores, na medida em que evidenciam, em seus discursos, uma necessidade maior do coordenador voltar sua atenção ao trabalho do professor, ao invés de dedicar tempo demasiado às questões técnicas e burocráticas, deixando a parte pedagógica "sacrificada".

Assim, percebe-se claramente o reconhecimento deste profissional nesta escola, como referência do professor no suporte de situações diversas relativas aos processos pedagógicos. Ademais, ao intervir em situações de imprevisibilidade, mesmo aquelas relacionadas com "as carências dos alunos e da família" que interferem no processo de ensino e aprendizagem, os coordenadores pedagógicos da escola básica, principalmente da esfera pública, subtraem o tempo que poderiam estar mais disponíveis ao professor.

Nesse sentido, o coordenador pedagógico precisa estar sensível às necessidades do professor, na troca de saberes, compartilhando as dificuldades e articulando juntos a busca de alternativas que visem à aprendizagem dos alunos. Cabe ao coordenador o desafio de fazer a tarefa pedagógica funcionar na escola, portanto, segundo Barros e Eugênio (2014, p. 10), 
esse trabalho não pode estar pautado somente nas necessidades emergentes do cotidiano, mas precisa ser bem elaborado, sistematizado em bases teóricas sólidas para resultar em uma prática coesa e real, tendo em vista que os problemas da prática não podem ser reduzidos a problemas meramente instrumentais, que conduzem a tarefa profissional a uma simplória escolha de aplicação e meios e procedimentos. Este profissional precisa prioritariamente estar consciente e seguro de suas funções para desempenhar realmente o seu papel de articulador, mediador e transformador da prática educativa desenvolvida pelos docentes.

Desta forma, a gestão pedagógica, para desempenhar o seu papel de articuladora, mediadora e transformadora do processo educacional, entre suas inúmeras funções, precisa garantir um tempo para a sua própria formação continuada para atuar em novos contextos, como os marcados pelas avaliações externas ou padronizadas. Essa necessidade ainda não é percebida nem acontece na escola pesquisada, como veremos na discussão da próxima seção.

\section{Gestão pedagógica e avaliação externa}

As avaliações padronizadas fomentam a cultura do desempenho com base em referências de mercado (comparar, medir, ranquear), aliando a qualidade do ensino ao desempenho dos profissionais da escola e à responsabilização pelos resultados. Assim, gestores e professores carregam o grande desafio de alcançar, por conta própria, as metas de melhoria da qualidade do ensino definidas pelo governo federal.

Essa realidade, bastante enfatizada pela literatura especializada, está presente no contexto da escola pesquisada, apesar da gestão pedagógica, no uso de sua "autonomia" profissional não focar o trabalho na busca de resultados quantificáveis, todavia, recebe orientações do sistema de ensino municipal sob a égide do Estado avaliador e regulador, como relatam as Coordenadoras Pedagógicas em entrevista:

[...] é a Secretaria Municipal de Ensino (SEMEC) que sempre procura trabalhar essa questão das metas nas reuniões de Coordenadores, mas a escola em si não tem um trabalho voltado para atingir a meta (C.2);

[...] a SEMEC exige que cada diretor faça por onde para que o Índice de Desenvolvimento da Educação (IDEB) aumente, então, a pressão começa lá em cima do diretor, aí vem para a escola e a direção começa a procurar alternativas [...] (C.1).

Trata-se de políticas que operam na esteira da descentralização da administração educacional, na centralização e no controle dos resultados e, no cotidiano da escola, traduzem-se na tensão permanente entre a racionalidade administrativa e a racionalidade pedagógica, ou na 
materialização de ações que ora assumem as marcas da gestão democrática, ora da gestão gerencial.

As próprias coordenadoras se contradizem quando falam que não trabalham na busca de resultados, mas acabam assumindo que existe um processo regulatório de cobranças, que começa do sistema de ensino para o diretor, do diretor para a escola. E esse processo complexo de “multirregulações" determinadas por um feixe de dispositivos reguladores (BARROSO, 2006) chega até o professor, através da Coordenação Pedagógica, quando passa a centrar mais em cobranças de questões burocráticas.

A ação regulatória age tão fortemente na mentalidade dos profissionais que atuam nas escolas relativamente à responsabilização pelo aumento do Índice de Desenvolvimento da Educação Básica (IDEB), que o próprio professor entrevistado se identifica como responsável pelo resultado:

[...] a sociedade precisa ter parâmetro, a gente tem que quantificar. Essa implicação da avaliação externa indica responsabilidade, significa que eu como professor sou responsável por um resultado [...] (P.1)

Aqui, responsabilização não é vista como estratégia imputada pelo Estado, potencializada em âmbito municipal e materializada na escola. Não que o professor no exercício do seu trabalho realizado com os alunos em sala de aula deva ser isento da responsabilidade com a aprendizagem, e consequentemente, por um resultado que é subjetivo referente a este processo, mas não é justo que apenas ele seja apontado como responsável por este resultado.

Assistimos a uma tendência da neo-taylorização do trabalho docente na transmissão eficaz de saberes de natureza predominantemente cognitiva, devendo ser mensuráveis e quantificáveis através de provas e testes "neutros" que avaliam a competência do professor através dos resultados dos alunos e a figura do gestor como principal responsável pela prestação de contas desse resultado e das metas definidas previamente (AFONSO, 2008).

$\mathrm{Na}$ perspectiva gerencialista, "a ênfase recai sobre a pessoa do diretor, buscando incutir performatividade junto ao corpo docente, visto que o objetivo maior é melhoria do desempenho" (KOETZ, 2010, p. 167). Percebe-se, aqui, uma mudança de foco quanto à responsabilização sobre a questão da aprendizagem, ou seja, uma minimização da importância de aspectos fatores externos (contexto social, cultural e econômico, condição desfavorável das escolas ao trabalho docente, etc.) e uma maximização aos fatores internos, centrados no desempenho do professor. Essa performatividade exigida ao trabalho docente encontra-se presente na política educacional realizada no município de Belém. 
Para Koetz (2010), as informações sobre as avaliações externas precisam "ser divulgadas e apropriadas pela comunidade escolar em processos de discussão coletiva" (p. 170-171). Ainda que as avaliações externas e, em larga escala, sejam constituintes de uma política nacional de cunho gerencial e merecedora de críticas (WERLE, 2010; PARO, 2011), quanto à sua concepção, seus métodos e instrumentos avaliativos, os seus resultados não podem ser ignorados.

Esquinsani (2010) deposita na figura do coordenador pedagógico a tarefa de viabilizar a análise dos dados das avaliações (tanto internas quanto externas), o que não é comum ocorrer no âmbito das escolas. Nesta perspectiva, os resultados das avaliações dizem respeito a duas dimensões da atuação do coordenador pedagógico:

a primeira como possibilidade de articulação pedagógica a partir do retorno/realimentação (feedback) que uma avaliação proporciona, o que implica planejamento e rearticulação de elementos no interior da escola. A segunda [...] na medida em que se consubstancia como instrumento de política educacional a ser decodificada, incorporado, explicitado na documentação legal da instituição, atribuindo sentido à política interna da escola, desenhando os contornos da mesma (Idem, p.140).

A autora destaca que os resultados das avaliações precisam ser divulgados, discutidos e incorporados no planejamento escolar, visando ao comprometimento de toda a comunidade escolar, porém, isso não tem acontecido na escola estudada. Não existem momentos coletivos para uma ação reflexiva sobre a apropriação dos dados das avaliações em larga escala, apesar de ser perceptível o compromisso do coletivo escolar e a preocupação em desenvolver um trabalho consequente com a aprendizagem dos alunos.

A importância que a gestão pedagógica atribui aos processos de aprendizagem em detrimento dos resultados quantificáveis são coerentes com um projeto de educação voltado para a emancipação, mas a condução do compartilhamento das tomadas de decisão e a organização e mobilização da comunidade escolar em relação a apropriação dos dados do IDEB e das avaliações externas, distanciam-se da proposta de uma concepção de educação na perspectiva democrática.

A não adesão ou mesmo o desprezo manifestado pelos profissionais em relação às políticas de avaliação nacional ocasionadas pelas reformas educacionais, contribui para que não aprofundem a complexidade da questão e fiquem isolados dentro das escolas, sem tomar alguma medida revertida na melhoria do ensino.

Deste modo, corroboramos com o entendimento de que compete ao coordenador pedagógico, mas também ao diretor realizar a mediação (administrativa, pedagógica e política) entre os dados divulgados dessas avaliações e as estratégias possíveis de serem efetivadas na escola em função da qualidade do ensino. 
Agindo nessa perspectiva, um caminho que poderá ajudar na reflexão dos processos de ensino-aprendizagem, é a aproximação do aluno com a avaliação através do conselho de classe/ciclo, pois "quanto maior for o interesse e o envolvimento deles para com a avaliação, mais eles percebem seu aprendizado como possibilidade de alcançar melhores índices nos testes" (SANTOS, 2010, p.151). Conduzir a avaliação, reafirmando a condição do aluno, enquanto sujeito responsável pela sua aprendizagem e por consequência, pelo resultado, a escola, passa a ganhar sentido não como valor, mas como processo que se constrói no fazer pedagógico.

Franco (2008) chama as capacidades de articular o aparato teórico-prático, de mobilizá-lo na condição presente em novos saberes a partir da prática, de saberes pedagógicos. Os saberes decorrem do exercício de uma prática reflexiva, intencionada, "realizada por um sujeito histórico, consciente de seus determinantes sociais, em diálogo com suas circunstâncias” (Idem, p.133).

O Conselho de Ciclo, instância avaliativa criada com o projeto Político Pedagógico da "Escola Cabana" em Belém na perspectiva emancipatória, realizado regularmente nas escolas com a participação coletiva (pais, alunos, professores, coordenador pedagógico, diretor) representa o espaço privilegiado de possibilidades pedagógicas para tratar as dificuldades e construir novos saberes.

Além desta instância de avaliação, existe o Conselho Escolar, órgão colegiado da escola, pelo qual deve passar toda a discussão frente às avaliações externas, desde o momento de aplicação dos testes e do recebimento dos resultados até o momento de (re)formulação do Projeto Político Pedagógico (PPP), diante dos objetivos para a melhoria das condições de ensino e aprendizagem (WERLE, 2010).

Essas práticas organizadas e articuladas somente são possíveis de serem materializadas com o trabalho coletivo, consubstanciado no PPP da escola e nos fundamentos da gestão democrática, por propiciar um maior comprometimento dos sujeitos com os processos formativos que atendam aos interesses da classe trabalhadora e da avaliação comprometida com a qualidade social da educação, entendida como processo complexo, provido de caráter político, crítico e inclusivo.

\section{Considerações finais}

A nova lógica de organização educacional em consonância com a política de avaliação centrada em resultados, vem se consolidando nacionalmente e trazendo implicações para as 
instituições de ensino, como a modificação dos fazeres pedagógicos que traduzam produtos quantificáveis.

A falta de apropriação e discussão reflexiva em relação aos resultados das avaliações em larga escala e do IDEB, contribui para o isolamento dos profissionais dentro das escolas, sem a compreensão da complexidade da questão e, portanto, sem condições de tomar alguma medida revertida na melhoria do ensino.

Partindo do pressuposto de que a gestão pedagógica abarca todas as práticas educativas voltadas para o sucesso da aprendizagem, sendo a organização desse processo diretamente relacionada às ações de diretores e coordenadores pedagógicos e efetivadas em sala de aula pelos professores, ratificamos que compete a esses profissionais, a condução do processo de divulgação, estudo e reflexão dos dados advindos das avaliações externas, numa perspectiva emancipatória.

\section{Referências}

AFONSO, Almerindo Janela. Avaliar a escola e a gestão escolar: elementos para uma reflexão crítica. In: ESTEBAN, Maria Tereza (Org.). Escola, currículo e avaliação. São Paulo: Cortez, 2008.

ARANTES, A. P. P.; GEBRAN, R. A.. O Curso de Pedagogia e o processo de formação do pedagogo no Brasil: percurso histórico e marcos legais. HOLOS, Ano 30, Vol. 6, p. 280 - 295, 2014.

BARROSO, João. O Estado e a educação: a regulação transnacional, a regulação nacional e a regulação local. In: BARROSO, João. A Regulação das políticas públicas de educação: espaços, dinâmicas e actores. Lisboa: Unidade de I \& D de Ciências da Educação, 2006.

BARROS, Séfora e EUGÊNIO, Benedito G. O Coordenador Pedagógico na Escola: formação, trabalho, dilemas. Educação, Gestão e Sociedade: Revista da Faculdade Eça de Queirós, Ano 4, nº 16, nov. 2014.

DOMINGUES, Isaneide. O Coordenador pedagógico e a formação contínua do docente na escola. São Paulo: Cortez, 2014.

ESQUINSANI, Rosimar Serena Siqueira. Tá lá, em cima da mesa: os dados das avaliações em larga escala na prática pedagógica. In: WERLE, Flávia O. C. (Org.). Avaliação em larga escala: foco na escola. São Leopoldo: Oikos; Brasília: Liber Livro Editora, 2010.

FERREIRA, Liliana Soares. Gestão do pedagógico: de qual pedagógico se fala? Currículo sem Fronteiras, v.8, n.2, p.176-189, jul./dez. 2008. 
FRANCO, Maria Amélia do Rosário Santoro. Pedagogia como ciência da educação. $2^{\mathrm{a}}$ ed. ver. ampl. São Paulo: Cortez, 2008.

HYPÓLITO, Álvaro Moreira. Estado gerencial, restruturação educativa e gestão da educação. RBPAE - v.24, n.1, p. 63-78, jan./abr. 2008.

KOETZ, Carmen Maria. Atuação da equipe diretiva e avaliação em larga escala: em busca de uma gestão democrática da escola pública. In: WERLE, Flávia O. C. (Org.). Avaliação em larga escala: foco na escola. São Leopoldo: Oikos; Brasília: Liber Livro Editora, 2010.

LIBÂNEO, José Carlos; OLIVEIRA, José Ferreira e TOSHI, Mirza Seabra. Educação escolar: políticas, estrutura e organização. 10ª edição revista e ampliada. São Paulo: Cortez, 2012.

LIMA, Maria Angélica Pedrosa; SANTOS, Diego Gomes do; SILVA, Thamine Araújo. O Coordenador Pedagógico e a construção de sua identidade: desafios e realidades. IV EPEPE, Caruaru, setembro de 2012.

PARO, Vitor Henrique. Crítica da estrutura da escola. São Paulo: Cortez, 2011.

PINTO, Umberto de Andrade. Pedagogia escolar: coordenação pedagógica e gestão educacional. São Paulo: Cortez, 2011.

PLACCO, Vera Maria Nigro de Souza; ALMEIDA, Laurinda Ramalho de; SOUZA, Vera Lúcia Trevisan de. Retrato do coordenador pedagógico brasileiro: nuanças das funções articuladoras e transformadoras. In: PLACCO, Vera Maria Nigro de Souza; ALMEIDA, Laurinda Ramalho de; SOUZA, Vera Lúcia Trevisan de (Orgs.). O coordenador pedagógico no espaço escolar: articulador, formador e transformador. São Paulo, Loyola, 2015.

PLACCO, Vera Maria Nigro de Souza; SOUZA, Vera Lúcia Trevisan de. O Trabalho do coordenador pedagógico na visão de professores e diretores: contribuições à compreensão de sua identidade profissional. In: PLACCO, Vera Maria Nigro de Souza; SOUZA, Vera Lúcia Trevisan de (Orgs.). O coordenador pedagógico: provocações e possibilidades de atuação. São Paulo, Loyola, 2012.

SANTOS, Almir Paulo dos. Relação entre aluno, avaliação e conselho de classe participativo, instância de reflexão. In: WERLE, Flávia O. C. (Org.). Avaliação em larga escala: foco na escola. São Leopoldo: Oikos; Brasília: Liber Livro Editora, 2010.

WERLE, Flávia O. C. Papel dos pais na busca de um padrão alto de democratização, acesso e permanência na escola. In: WERLE, Flávia O. C. (Org.). Avaliação em larga escala: foco na escola. São Leopoldo: Oikos; Brasília: Liber Livro Editora, 2010.

Recebido em: 30 abr. 2019 / Aprovado em: 06 nov. 2019

\section{$\underline{\text { Cite como }}$}

LÉLIS, Luziane Said Cometti; HORA, Dinair Leal da. A gestão pedagógica no contexto das avaliações externas e em larga escala. Dialogia, São Paulo, n. 33, p. 72-85, set./dez. 2019.

Disponível em: https://doi.org/10.5585/Dialogia.n33.13782. 